\title{
Information Privacy Issues in the Information Age
}

\author{
Netiva Caftori \\ Northeastern Illinois University, \\ Chicago, IL, USA
}

\author{
Steve Teicher \\ University of Central Florida, \\ Orlando, FI, USA
}

n-caftori@neiu.edu
Steve-Teicher@att.net

\begin{abstract}
Information privacy is the primary issue discussed in the majority of papers about e-commerce security. We observed and confirmed from literature that while privacy is a voiced concern of consumers, it is not the insurmountable barrier to doing business. There are other information accuracy and operational issues that add or detract from consumer experience. We will discuss these using real-life anecdotes.
\end{abstract}

Keywords: information privacy, security, trust, convenience, continuous observation, real-life anecdotes

\section{Introduction}

Convenience and security are both enhanced and threatened in the Information Age. For example, one used to fear getting lost or having a breakdown far from the nearest friendly phone. Now the GPS (Global Positioning System) locates the car. If the car breaks down, the driver pushes a button and the On-Star operator is ready to provide help already knowing the location of the vehicle. The central service can remotely unlock a car for a customer who locks the keys in the vehicle. Typically the central service will ask the customer for a password for identification. A customer who needs new travel tickets to alter an already reserved flight can do this at any travel agent. Bars that identify their clients by swiping the client's driver's license through the reader get sufficient information from the fast swipe to do target marketing (NY Times "Finding Pay Dirt in Scannable Driver's Licenses")

However, there is another perspective, as seen in the February 24, 2002, NY Times editorial "Technology's Threats to Privacy." The editorial bases its argument on the recent discovery that the Microsoft Media Player (Media Player is a program that can change certain data sent over the Internet into sounds that have the fidelity of compact disks) keeps tabs on MP3 downloads by Windows XP users and may from time to time report summaries to Microsoft. While the NY Times editorial correctly identifies a privacy problem with Microsoft, our observation is that the consumer issues with e-commerce systems include a lot more than privacy.

We began developing this paper using anecdotal stories about the highly-debated issue of privacy in the Information Age. We were curious how this key issue manifests itself in real-life examples. We believe citizens are concerned about privacy but become more upset when their time or their assets are negatively affected.

We found a significant study on Internet privacy by Lee Rainie et al, titled Trust and Privacy online: Why

Material published as or in print, is copyrighted by Informing Science. Permission to make digital or paper copy of part or all of these works for personal or classroom use is granted without fee provided that the copies are not made or distributed for profit or commercial advantage AND that copies 1) bear this notice in full and 2) give the full citation on the first page. It is permissible to abstract these works so long as credit is given. To copy in all other cases or to republish or to post on a server or to redistribute to lists requires specific permission from the publisher at Publister@intormingscience.org Americans want to rewrite the rules. With a sample size large enough to fairly represent the general population, the survey confirmed our observations that individuals clearly appear to be concerned about privacy, yet they opt to share information when the sharing renders them some advantage.

Individuals want the law to protect privacy rights. Over $94 \%$ of individuals want privacy violators to 
be disciplined, and a significant number, $11 \%$, say that the owners of companies that violate privacy should be jailed. Despite what they say, individuals still share private information to get better service.

\section{The Experts Argue over Convenience and Features versus Security}

Consumers want and believe they need the ability to send complex documents over the Internet. For instance, many are involved in businesses that make use of Web cookies, or online FLASH presentations, etc. These features add vitality to the Internet. They also make systems more vulnerable to intrusionshence the argument concerning the tradeoffs between functionality and security.

Recently Bill Gates, founder, chairman, and Chief Technical Officer of Microsoft, directed a large number (advertised as over 7,000) of his developers to focus their energies on making Windows more reliable and more secure. Security experts Bruce Schneier and Adam Shostack wrote a paper called "Results, Not Resolutions" to give Microsoft some advice on how to proceed. Schneier and Shostack's advice favored reducing the risk of intrusion by reducing functionality.

Not everyone agrees with these two security experts. Robert Graham, also a security expert, retorts in his paper Security is a Superstition that Schneier and Shostack understand security but not business. Graham points out how consumers want convenient sharing of complex documents. Graham argues that Microsoft is pleasing its customers and that the customers are accepting increased risk to have the features.

Discussion of Internet security tends to focus on "cookies" or on viruses; however, as we observe these Internet intrusions are not our only problems. Our convenience, privacy and security can be threatened by database and system problems that are not related to cookies or network intrusion.

Damage in two of the following stories is due to errors in design or in implementation and to a lack of clarity in accountability for errors. Today the burden of computer system problems that harm individuals tends to be carried by the individual who is harmed, rather than by the supplier of the service, the computing systems or the software.

If an airline damages luggage, the owner expect compensation. If a computer system gives the wrong answer to the DMV and causes hassle, there is no expected compensation. Why is this?

\section{Application Construction Methodology Effect on Risk}

The popular form of providing the human interface to most types of database systems today is via the WEB whether over the public Internet or a private intranet. This means that a WEB browser is used as the mechanism to display and to collect information from the client. Behind the WEB Browser, hidden from the user are many system elements such as databases, logic engines, networks, security servers, load sharing devices and more. Sometimes computing services constructed in this manner are called by the name E-Commerce Systems. We use this name, E-Commerce, whether or not the purpose of the service is for a profit financial transaction or the issuing of a driver's license by a government agency.

E-commerce WEB based systems are often described as being "n-tier software" because layers of the system, such as human interfaces, business logic, and database can be developed independently by specialists to objective specifications and then hooked together in a variety of configurations to form the computing solution. The precise configuration often depends upon the customer load, the amount of money that the business can spend, and the arrangements with the hosting service. The risks happen because of at least the following issues:

- Rather than isolating activities into a coherent architecture developers sometimes put functions where it is convenient at that moment. This is like the electrician wiring a home deciding to put the switches that control the kitchen light outside the house, because this is where the electrician 
was working when he or she decided to install the switch. Much later when the occupant of the house decides to turn on the kitchen light, the occupant has to do a lot of searching to find the switch. A repair person called to fix the kitchen light might be mystified that none of the switches in the kitchen area control the circuit. This same phenomena happens when software is built without a coherent enterprise architecture. The user sees buttons on pages where they are not expected. Software maintenance teams have difficulty isolating bugs and making repairs that work. The software maintenance engineer thinks she has fixed a bug, but it is not fixed.

- The popular software construction method is now OOP or Object Oriented Programming. Popular languages used to construct E-Commerce Systems such as Java, $\mathrm{C}++$, and Visual Basic encourage and support OOP. In this methodology, applications programmers make use of components in which they supposedly have to know only the interfaces. What happens inside a component is theoretically not the concern of the programmer. The problem with the theory is that there could be logic situations inside the component which if known to the application programmer would explain deviant system behavior. Many times the component is provided as a library that is incorporated at the run-time of the application. The source code and design of the internals of the component are often not made available to the applications developer. Even if the component design were made available to the applications developer, that person may lack the skill and the time to check out the component.

- Production system configurations are often vastly different than development and test configurations. Application operation and especially security are often affected by system configurations.

- Testing is often compromised in the development process as it is often done last and appears to management to delay deliveries. Testing is very difficult for modern E-Commerce systems because of the great number of test cases that need to be run, and because it is often necessary for a human to look at the screen to confirm whether a particular test has succeeded or failed. Testers often have to work with a compromised database, i.e. one that is smaller and less complex than what will be found in production.

- Faculty who understand e-commerce details are limited, so that schools and universities produce an insufficient number of trained developers. This means that e-commerce development shops are often missing individuals with the qualifications to do the job.

\section{Anecdotal Observations}

While many are concerned about privacy and security, people appear to favor convenience over privacy when faced with a decision. People purchase house and vehicle alarms, and yet they will go to a hotel or fancy restaurant and hand their keys to a stranger at the door. This person hands out a ticket that essentially says, "The Establishment is not responsible for any problems encountered by this vehicle." Will the car be stolen, damaged, or be involved in an accident while it is beyond the owner's control?

Similarly we observe, and the previously mentioned Rainie study confirmed, that individuals will share significant personal information when the sharing helps increase the convenience of activities such as arranging travel, acquiring loans, or getting medical care. Why do individuals say they are concerned and yet share confidential information over such insecure channels? There are several possible reasons:

- Few people have been badly damaged by Internet theft. Therefore, users are concerned but not ready to drop convenience without sufficient evidence of threat.

- Comprehension of Internet technology and computing is sufficiently low that individuals do not take effective steps to protect their data. The Rainie study says, less than $50 \%$ of Internet users can 
identify "cookies" and only $10 \%$ have set up their browsers to reject them. Of course, this number might change now that Microsoft has made it easier to configure Web browsers to reject cookies.

- Most individuals including the general public, system administrators, executives, etc. are unfamiliar with the e-commerce development process and trust software developers to do the "right" thing. Trust is often misplaced.

\section{What We Observed}

We cite particular examples, which are clearly typical. Many individuals do not recognize these examples as either computer system issues. Consider a software developer who builds an application that satisfies the buyer, who happens to be a manager in the department of motor vehicles for a state. The buyer may not even care if some small percentage of the public is inconvenienced. The buyer may not know that the software could have been done in a way that reduces hassle for individual drivers.

Below we start with a system that is done right from the point of view of the end client, the traveler. This system definitely compromises privacy, but the travelers like it. Later we discuss systems that do not work so well in satisfying the client, but that in fact do a good job of preserving privacy.

\section{The Travelers}

In August of 2001, a married couple who had different last names made reservations through an offairport ticket agent to travel on a major airline from Florida to Italy. This involved flights from Florida to NYC and then NYC to Rome during the last week in November. In October, when this couple happened to be on their way to Boston, they stopped at an airport ticket agent. The agent was not busy, since it was the first-class line, so the couple also inquired about their November travel plans.

Using only one name, the travel agent was able to pull up the couple's entire reservation and informed them that the flight from NYC to Rome had been cancelled due to post-9/11 flight cutbacks. The couple was distressed and asked for help.

Within one minute the ticket agent was able to pull up all information, including fares, and re-book the trip to go from Orlando, via Miami, to London and then to Milan. This involved flights on 3 airlines rather than one as before. Also, the agent maintained the original low-fare (cost approximately $\$ 600$ rather than over $\$ 5,000$ ), business-class ticket by indicating that the re-booking was "an involuntary reroute." This classification of booking required the agent to get approval from a supervisor, which she did in seconds.

Let us look at the situation from a privacy viewpoint. Using only one last name and an approximate date, the booking agent could access the itinerary for both individuals, including all relevant information about them: such as physical addresses, payment information, individual travel history, etc. Any agent could

have done this, since the couple was not required to divulge any passwords or secrets besides the name of one of the travelers, one destination, and the travel date.

Frequent travelers are accustomed to sharing information that assists them in their pursuit of convenient travel. They do not seem to worry that the same travel system that provides helpful information to the ticket agent could also provide helpful information to a house burglar or others who have less-thanpositive intentions. The mere knowledge that someone is a Platinum traveler on some airline could alert a robber that a particular house will be frequently vacant.

Individuals appear very willing sacrifice privacy for convenience when they travel.

\section{Paul Could Not Get a Driver's License}

Paul passed the test for his driver's license in 1985 in Massachusetts. He lived in Massachusetts until 1991, when he moved to California. Having a clean driving record, including 6 years of driving experi- 
ence without an at-fault accident, he had no problem getting a license and insurance for a new car in California.

Then in 1997, Paul moved to Florida and applied for a Florida driver's license. He was refused because a State of Maine computer system listed Paul as having a suspended license. Paul had never lived in Maine nor had a Maine driver's license; therefore, he was surprised and annoyed.

The Florida Division of Motor Vehicles provided Paul with a number to call in Maine, but the number on the computer printout was incorrect. Paul did reach someone in Maine who informed him that an outstanding \$10 parking ticket from 1987 was creating the problem. That parking ticket was one of the few negative marks in his record. Most people would have ignored it. To Paul it was a big deal so he just happened to have the canceled check. This is a good thing for him because as of 1997, the State of Maine would have wanted at least $\$ 17$ plus additional fines for ignoring the ticket.

It still took over 30 days, after Paul discovered the problem and mailed Maine a copy of the canceled check, in order to clear up his record in the various computers so he could obtain a Florida driver's license.

\section{Analysis of the Situation with the Driver's License}

Paul's problem was not his error. However, he had to do the legwork to obtain approval for a driver's license. The error was caused by several different systems:

- Initially, some agency in Maine with the authority to hand out parking tickets and fines was not accountable enough to ensure that paid fines resulted in a clearing of the appropriate flags in the violations database.

- By the same token, the agency in Florida that wires itself into the information from other states is not accountable enough to make corrective actions when there is a mistake. In fact, the agency could claim that they did their job by preventing a "violator" from getting a Florida driver's license.

- As systems are moved from mainly human operations to mainly computerized ones, agencies tend to trust the data from the machine without testing it for accuracy. For instance, if Paul had proved that he never lived in Maine and had no driving problems in his previous states of residence, then a human being might question the flag that prevented him from receiving a Florida license-yet the machine is not programmed to evaluate the issue and ask questions in different ways to get at the truth.

- When there is a problem, and the damage is mainly upon the individual, no government accountability or business accountability exists unless the individual creates a legal disturbance. Even though several days of dedicated time and long-distance calls resolved Paul's problem, the notable fact is that Paul had to do all the work himself. The designers who made the mistakes in the database programming may never even learn of the problem. The problem that happened to Paul can happen again and again.

\section{Note that in Paul's Case Privacy was Maintained}

The true confidential information concerning Paul was not compromised because State of Florida was not told the full nature of the problem. Rather, it was simply told that Paul was not allowed to drive in Maine because of a violation. In this case, Paul likely would have preferred that his private information be made public. If someone of authority in Florida had been able to see the nature of the violation, and verify the canceled check, perhaps that person could have over-ridden the database flag. 
Information Privacy Issues

\section{Driving School is the Answer to Repair a Database Problem}

One of the authors of this paper was caught speeding in a construction zone. To avoid having "points" that would increase insurance premiums, the author decided to attend traffic school. This is a four-hour session in which violators meet with an instructor who is in complete charge during that time. There is no eating or drinking in these sessions and no cookies. One of the exercises was for each to tell the group what he or she did to land in this situation.

The conversation in the room was the typical "I did not see the stop sign" style of banter. However, when a city worker came up for his "time in the barrel," he said that he had done nothing wrong. In fact he had done something right. He had parked his truck in a lot, and upon leaving in the afternoon he noticed that the light pole near his truck was about to fall over. Rather than leave it in this state, he called his office and agreed to wait on the spot until the repair crew arrived.

During his wait, a local policeman arrived and without hesitation gave the city worker a ticket for running into the sign. The city worker had not hit the sign, and in fact, there were no dents on his truck. After help arrived, the city worker spoke to his supervisor and cleared up the situation almost completely.

The one issue that was not cleared involved points on his driving record. As it turned out, the only way to clear his driving record was to go to driving school. This snag might have been built into the database system to prevent "fixing" of traffic tickets. However, in this case it caused the city worker to attend classes when he really received a citation by error.

\section{Analysis of the Driving School Case}

The system that caused the problem was likely optimized to prevent "fixing" of traffic violations. The only way to remove the points that come with a violation was to attend traffic school. Either the possibility of correction due to an error was not considered, or the system developers were told to ignore something that rarely happens. We presume that relief would be readily available if the consequences were worse than attending traffic school.

However, the question would have been more difficult if the individual had received another traffic violation in the same 12 months as the incorrect one. State law requires that traffic school can only be attended once in 12 months and 5 times in a lifetime. Therefore, if the city worker had been in a "penalty situation," the complexity of this issue would undoubtedly increase.

Again we see a situation similar to the one that affected Paul. The system design did not allow for a correction. Also, this is a case in which privacy was not the main concern of the individual. The city worker was merely concerned about having to waste 4 hours in a driving school and what might happen to his insurance rates.

\section{Where are we Headed?}

E-Commerce and Information technologies using the Web and other communications channels will have an increasing effect on our lives:

- The National ID card may or may not happen, but the equivalent of linking multiple databases in an uncontrolled fashion is happening and will continue for many reasons:

○ Security - Patterns will help identify folks who may do harm.

- Clearly the INS could have done a better job working with a national integrated database to avoid granting visas to terrorists. The granting of visas to people already dead can be considered a joke. However, there is a suspicion that there are others who might still be active. 
- Convenience - Businesses and government can serve clients better if they know more about them and clients appear to respond positively to better service.

- Efficiency

- A key to raising global standards of living is to reduce waste. Databases and elaborate linking can enable more accurate reductions in waste. For instance, a national energy authority could analyze every individual's energy use and provide each of us with personal guidance on how to reduce our waste. As an example all achieved miles per gallon of a certain model car in a given area could be measured and each individual driver could be compared against the statistics for all such vehicles. The owners of vehicles that did not achieve the mean miles per gallon could be warned or perhaps awards could be given those who drive more efficiently.

- The technology to make this possible is now being shipped with new cars.

- The location technology is part of the anti-theft and the emergency help systems.

- The engine monitoring technology is part of the emergency help system

- Safety

- We want to use new techniques to constrain the guilty and avoid interfering with the innocent.

- Systems that provide a continuous monitor of our location and our activities are now available.

- Personal safety could be improved by systems which locate us.

- For instance, the director of Information Services for non-profits for the City of Hong Kong noted that they had a large number of older folks who often get lost. A badge pinned to their clothes with a GPS and cell phone chip could be used to locate these elderly people.

- Similar locating systems could be used to locate children or pets. The GPS device could be built into an object that the children wore or into a pet collar.

- $\quad$ Banking and Investment Systems

- Less paper, faster transaction processing, and greater visibility can happen with Web-based systems, and brokers are adopting them.

\section{Some Issues Include}

- An audit of stated privacy and reliability policy versus technical and administrative implementation is needed.

- Pilots and electricians require training and documented practice before being licensed. Is there need to be a similar licensing for individuals who construct and who operate certain classes of information and e-commerce systems?

- Lawrence Lessig and others identify issues that cry out for protective legislation. Some of this legislation needs to be in the form of traditional laws, and some may need to be in the form of interface requirements implemented by publicly tested code.

- There are certifications for components, such as those used in commercial aircraft construction. Should there be similar certifications for software components used in the construction of information and e-commerce systems? 


\section{What Next?}

We are convinced that education plays a critical role in maintaining the use of information and ecommerce systems to make a better world for all of us. This better world will be more efficient, more convenient, and less wasteful. If we get bogged down with fear because of the damage that is caused to individuals by such systems, then we can lose the advantages of these technologies.

We see some next steps:

1. Go beyond the concerns about privacy as the key issue that can damage individuals who are affected by information and e-commerce systems.

2. Move the accountability away from the individuals who are affected back to those who build and implement? We do not ask passengers to improve air traffic safety or luggage handling.

3. Improve education and testing of those who build and operate information and e-commerce systems.

\section{References}

Faughnam, J, (2001), International Net-Based Credit Card/Check Card Fraud with Small Charges, http://www.faughnan.com/cctraud.htm/

Frosch-Wilke, D. (2001). “Are E-Privacy and E-Commerce a Contradiction in Terms? - An Economic Examination.” Informing Sciences.

Graham, R. (2002), Security is a Superstition, http://Www.robertgraham.com//ournal/020210-superstition.htmI

Graham, R. Presentations, http://www.robertgraham.com/sides/default.htm

Lessig, L., (1999). Code and Other Laws of Cyberspace. New York. Basic Books

Microsoft, 1998. Developing for the Enterprise. Redmond. Microsoft Corporation.

Neumann, P. 1995. Computer Related Risks. New York. ACM Press

Lee, J., 21-March-02. "Finding Pay Dirt in Scannable Driver's Licenses”. New York Times

New York Times. 24-February-02. “Technology's Threat to Privacy” New York Times

Rainie, L., Horrigan, J., Lenhart, A., Spooner, T., Carter, C., (2000), Trust and privacy online: Why Americans want to rewrite the rules, ittp://www.pewinternet.org/reports/toc.asp?/Report=19

Rotenberg, M. Agre, P. 1998 Technology and Privacy: The New Landscape. Cambridge. MIT Press

Schneier, B., Shostack, A. (2002), Results, Not Resolutions, http://online.securitytocus.com/news/315

\section{Biographies}

Since 1982 Dr Caftori, a prominent artist has been a professor of Computer Science and Women's Studies at Northeastern Illinois University in Chicago. Dr Caftori was born in Israel and began her education there. She completed her high school Baccalaureate from Ecole Alsacienne in Paris, France. She later studied Mathematics and French at Tel Aviv University. Professor Caftori completed her BS, MS, and Doctor of Arts degrees in Mathematics and Computer Science from University of Illinois in Chicago. She has extensive industrial experience as a programmer and systems analyst. Dr. Caftori has served as an officer in the Israeli Defense Forces prior to becoming a US citizen. More about Dr Caftori is found on her WEB site, WWw.ne1u.edu/ ncattor1.

Steve Teicher is currently an industrial partner and research associate at the University of Central Florida in Orlando. Mr. Teicher has a BS degree from MIT in Electrical Engineering and an MBA from Rollins College. For more than 35 years he managed development groups producing more than two dozen major products and significant software systems.

Both Caftori and Teicher are active board members of Computer Professionals for Social Responsibility. 